of a few pounds, since those impurities which are of greatest interest from a metallurgical point of view, for example, carbon, sulphur and phosphorus, are those with the most favourable distribution coefficients. The water-cooled hearth obviates contamination from the crucible and is more readily adaptable to a large scale than floating-zone refining. A 3-lb. ingot of iron was shown with a carbon content of 4 parts per million over most of its length. By further purification of the gas atmosphere over the specimen it is hoped to reduce this to 1 per million. Such iron will have considerable interest for the study of the movement of dislocations, using transmission electron microscopy.

The provision of a highly stable frequency standard by optical pumping of a cæsium gas cell was demonstrated by the Standards Division. Stabilities of \pm 4 parts in $10^{11}$ have been obtained over a few hours and \pm 1 part in $10^{10}$ over six months. Cæsium vapour is contained in a small cylindrical glass cell. The illumination of this with resonance spectral lines from a cæsium lamp causes a redistribution of the energy states of the atoms (optical pumping) with some absorption of the light, detected by a photocell. When a microwave field at the crsium hyperfine transition frequency is applied to the cell more light is absorbed since the energy-level distribution tends to return to normal. As the microwave frequency passes through the hyperfine transition value, therefore, a small but sharp decrease occurs in the transmitted light. Frequency modulation of the microwave field, at a low frequency-rate, produces a low frequency output from the photocell, the phase of which is dependent on which side of the transition the mean microwave frequency lies. This phasesensitive signal can be applied to pull a quartz oscillator the multiplied frequency of which gives the microwave frequency. The frequency stability of the system is determined by the constancy of various factors affecting the shift of the hyperfine transition frequency; these are the buffer gas in the cell, the light intensity, the temperature and the magnetic field.

The Standards Division also displayed an infra-red monochromator and specially designed furnaces to show how monochromatic radiation in the infrared could be used to realize the thermodynamic scale between $200^{\circ} \mathrm{C}$ and $1,063^{\circ} \mathrm{C}$ by means of Planck's law of radiation. This has been rendered possible by the development of sensitive photo-conductive detectors of infra-red radiation, such as the leadtelluride cell.
The Aerodynamies Division exhibited a general cross-section of its basic research in relation to flight of aircraft. Much of the recent work has been concerned with stability and flutter properties of new aircraft shapes and their structural strength under severe conditions of flight at supersonic speeds. The Division displayed a series of experiments dealing with slender wings in unsteady motion. Knowledge is being gained of the aerodynamic forces relevant to the transient effects of a gust and of possible structural deformation of wing surfaces linked with oscillatory behaviour. The work shown included a water-tunnel study of the flow under certain conditions of transient motion and the measurement of oscillatory forces and surface pressures on rigid and deforming delta wings in a low-speed wind tunnel. On display also was a newly designed apparatus for the measurement of oscillatory forces on sting-mounted models in transonic, supersonic and hypersonic flow.

Apparatus on view in the Autonomics Division demonstrated an attempt to develop a high-speed character recognition machine capable of reading the results printed out by normal cash registers and listing machines. The operation of the machine is based on multiple auto-correlation techniques devised in the Division. It uses a novel combination of scan displacement and video signal delay to obtain a multitude of copies of any character placed before a flying spot scanner. Groups of copies are correlated in a manner which defines and measures the amount of distinctive features present in the character scanned. The character can then be identified from the statement of features present. It is anticipated that the reading speed will exceed 1,000 characters per sec.

Because of the inherent difficulty of displaying their work the Mathematics Division listed the main items of their research and visitors were invited to discuss those of interest to them with members of the Division. Specific demonstrations were also arranged if required.

The staff of the Laboratory welcome the opportunity during the open days of showing the latest developments in their work to other scientific workers and to technical staff from industry. In particular, these occasions offer industrial firms a chance to discover in what ways the work of the National Physical Laboratory may be of interest to them. The open days in 1963 will be held during May 15-16 and applications for invitations should be addressed to the Director, National Physical Laboratory, Teddington, Middlesex. J. R. IllingworTH

\title{
MARINE SCIENCE LABORATORIES, MENAI BRIDGE
}

\author{
By DR. D. J. CRISP \\ Director
}

\begin{abstract}
$\mathrm{T}$ HE opening of the Marine Science Laboratories of the University of Wales on June 5 by Sir Harry Melville marked the end of the first ten years of growth of the Marine Biology Station and the beginning of further developments in oceanography. In his opening address Sir Harry referred to the fruitful areas of research lying between established disciplines and congratulated the University College of
\end{abstract}

North Wales on its foresight in planning for the integration of marine biology with a new department soon to be established in the cognate subject of physical oceanography, so that effective collaboration in all aspects of oceanography-physical, chemical and biological-would be encouraged. The buildings have therefore been renamed the Marine Science Laboratories. 


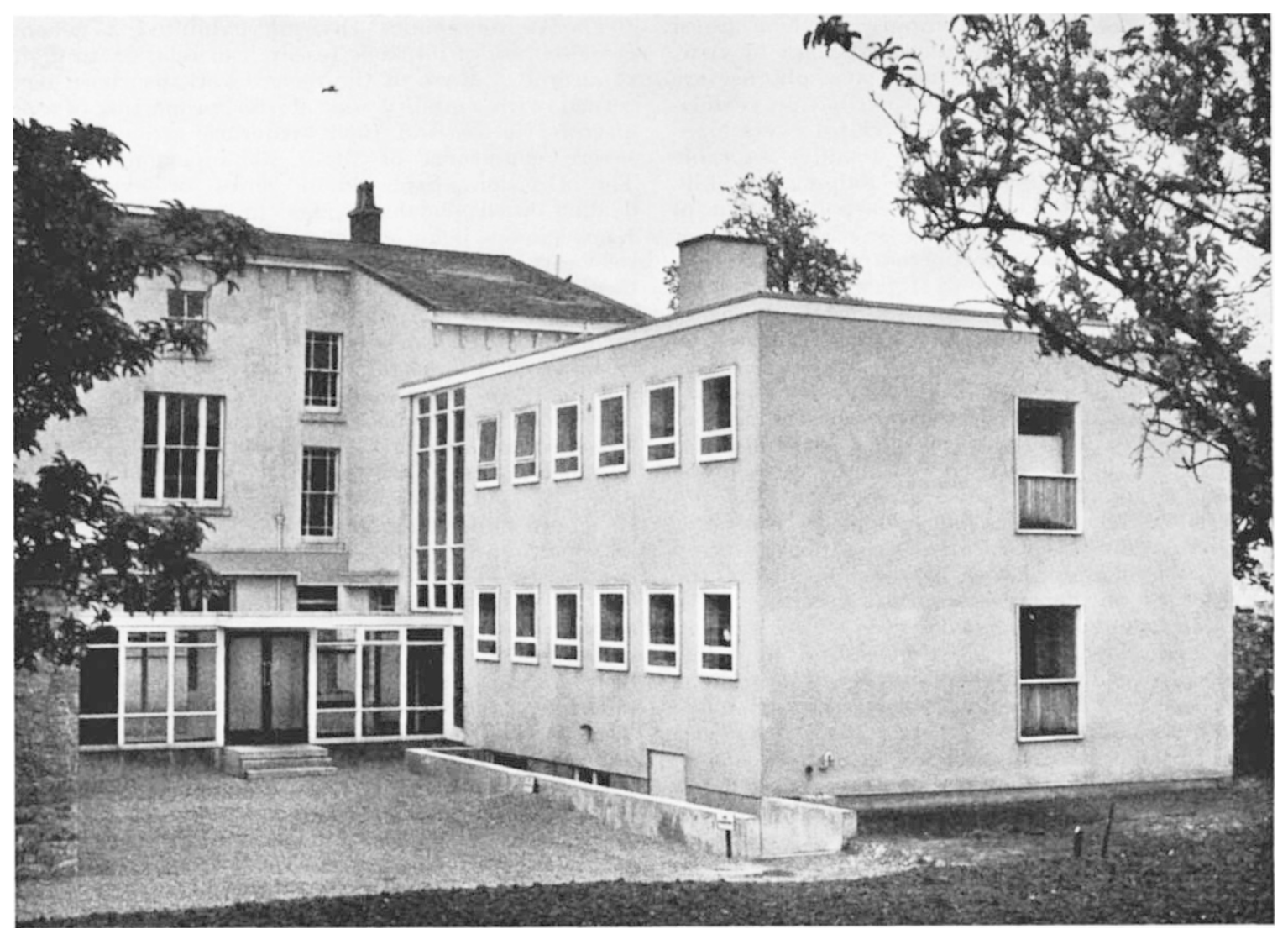

Fig. 1. The Marine Science Laboratories of the University of Wales, at Menai Bridge, Anglesey, showing the new research wing

The devolopment of the present site overlooking the Menai Straits began in 1953 when the University College, as a temporary measure, took over and adapted an existing house. In 1958 additional land and the adjoining house were purchased, so making it possible to establish the permanent laboratory there. A new two-storey research wing (Fig. 1) and a new single-storey teaching wing have now been added to the existing buildings, a marriage of convonionce skilfully and successfully contrived by the architects, Sir Percy Thomas and Son of Shrewsbury. These extensions were built by Pochin (Contractors) Ltd., Middlewich, and the whole cost $(\mathfrak{£ 3 7 , 0 0 0 )}$ was provided through the University Grants Committee by means of a direct grant to the University College of North Wales, supplemented by grants generously rolinquished from their quota by each of the other Colleges of the University of Wales. An additional grant of $£ 22,000$ was made for furniture, fittings and scientific apparatus.

The buildings form three sides of a small court open to the north-west. The teaching wing occupies the north-east side, the research wing the south-west side, while the original three-storeyed building completes the south-east side of the court. Communication between the two wings of tho building is provided by a link corridor.

The teaching wing contains a laboratory for thirty students, which is oquipped with supplies of running sea-water and compressed air, as well as the usual services. The 'butterfly' roof construction in this part of the building has permitted an unusually tall north-facing window to bo supplied, so that the laboratory is always light and cheerful. Adjacent is an equally bright and attractive seminar room, suitable for classes of up to thirty students and for small conferences. The teaching accommodation is used in term time for courses in oceanography, and is available during the vacation to visiting groups of students pursuing field courses and to visiting research workers. The under-bench cupboard and drawer units are movable so that the laboratory can be simply adapted to whatever use is roquired.

The new research wing includes four well-equipped research laboratories with windows opening on the north-east side. Those on the ground floor are designed for biological work, those on the first floor for biochemistry and microbiology, in keeping with the general arrangement of research in the rest of the building. Marine zoology is conducted mainly in the laboratories on the ground floor, from which there is easy access to the research aquarium in the basement, where animals can be maintained at a temperature little removed from that of the sea. Lead-covered 'wot benches' and supplies of sea-wator are also provided in most of the research rooms to allow marine animals to be kept continuously under observation. The sea-water to these rooms is gravity fed from tanks kept filled from the sea, and noncorrodible materials have been used throughout the sea-water system. The second floor of the building is well equipped for chemical and biochemical work and also houses the algology soction with an aquarium room for growing marine algae under laboratory conditions. The two laboratories on the third floor are at present being used for physical oceanography, 
foreshadowing further developments in this field which are planned to take place during the next five years. In addition to a total of thirteen individual research rooms, the laboratory possesses a large workshop, dark rooms for photography and physiology, instrument and balance rooms, a glass-blowing room and a cold room.

Built in spacious Victorian style, the original houses have contributed to the domestic amenities with little modification. The common rooms for staff and technicians are served from a small kitchen, which is available not only to provide coffee and tea for the usual breaks but also for individuals to prepare their own meals-a facility greatly appreciated if working late into the night on material collected on the evening low-water. The rapidly growing library and the reading room occupy the whole of the second floor of one of the houses. Most of the current periodicals in marine biology and oceanography are now taken by the library and a volume of collected reprints covering the fields of taxonomy, ecology, behaviour, physiology and biochemistry is exchanged annually with other laboratories all over the world. The whole building has been decorated throughout in pleasing contemporary style, with the effect of blending the old and new fabric.
At present there are six teaching staff, four fulltime research staff employed on projects supported by bodies outside the University, and twelve staff employed in technical, secretarial and other capacities. There are eight postgraduate students and, during the first year in which the teaching wing has been used, some ninety undergraduate students from the University of Wales and from elsewhere have received instruction in courses covering marine zoology, algology and physical oceanography and limnology.

No account of the laboratories would be complete without reference to the site itself. The laboratories stand less than fifty yards from the floating stage of the pier to which large and small boats can be moored and from which sea-water can be pumped at all states of tide. The Menai Straits themselves afford safe anchorage within easy access of the Irish Sea. The hitherto unspoiled coasts of Anglesey and Caernarvonshire sustain an exceptionally rich and varied marine fauna and flora. Combined with these practical advantages, the laboratories enjoy a situation of great scenic beauty, having a commanding view of the Menai Straits from the Telford Suspension bridge to the west as far as Beaumaris Bay and the Great Orme to the east.

\section{MENTAL HEALTH IN THE UNITED STATES}

GEVERAL significant events with far-reaching implications for mental health occurred in the United States in 1961. A notable milestone was the publication of Action for Mental Health. This report presents the findings of a six-year study by the Joint Commission on Mental Illness and Health, authorized by Congress in 1955 to evaluate the needs and resources of the mentally ill in the United States and make recommendations for a national mental health programme.

The Commission included representatives of 36 national organizations. Among its findings are: that the demand for public mental health services is still largely not met, in spite of the great gains made during the past decade; probably not more than 20 per cent of the 277 State mental hospitals have participated in innovations designed to make them therapeutic as contrasted with custodial institutions; the average proportion of general State expenditures allocated to mental hospitals has declined in recent years; an average of 4.72 dollars per patient per day is spent by State hospitals, as compared with $31 \cdot 16$ dollars for community general hospitals and 12 dollars or more for Veterans Administration psychiatric hospitals; the persistent attitude that schizophrenia is incurable is false. With proper treatment the schizophrenic has a 3 in 5 chance of leading a useful life in the community; and the rejection of the mentally ill by society has been a major factor in the lag in effective treatment. More helpful attitudes should be created.

The Commission recommends that there is a need for more long-term and basic research in mental illness; in patient care, emphasis should be devoted to breaking down barriers between hospital and community; providing more immediate help and extending care of mental patients through clinics and other agencies; improving the therapeutic milieu in the mental hospital and developing after- care programmes; the pace of recruitment and training for all categories of mental health should be accelerated; efforts should be made to increase the use of non-medical mental health workers; more adequate intensive treatment of acutely ill patients is needed; one fully staffed mental health clinic is needed for each 50,000 population; more psychiatrists in private practice should be encouraged to participate in community clinic services; psychiatric units in all community general hospitals with more than 100 beds are desirable; new State hospitals construction should be confined to intensive treatment centres of 1,000 beds or less; and a programme should be eventually developed whereby the Federal Government shares with individual States the cost of mental patient services, over and above present and future programmes of Federal grants-in-aid for research and training.

A special State Governors' conference on 'Mental Health" was held in Chicago during November 1961, to discuss directions and emphases for effective planning for more adequate care and treatment of the mentally ill. At the two-day meeting the Governors expressed their concern for what they described as "the number one health problem of the Nation" by drafting resolutions calling for accelerated action. They commended the Joint Commission for its study and endorsed the concept that Federal, State and local government as well as private and voluntary efforts must be combined to achieve goals sought.

Another event was the publication of the Report of the Surgeon General's Ad Hoc Committee on Planning for Mental Facilities. Its major rocommendations include: (1) the establishment of community-based mental health facilities offering a wide spectrum of services, as part of a co-ordinated system of Statewide health services; (2) stimulation of comprehensive planning for mental health facilities by action of the Governors of the State, through designation of an existing agency or appointment of a planning body 